\title{
Acompañamiento terapéutico: práctica y clínica en un hospital psiquiátrico.
}

Therapeutic accompainment: practice and clinic in a psychiatric hospital.

\author{
María Teresa Rosique ${ }^{a}$, Carmen González de Vega ${ }^{\text {b }}$, Teresa Sanz ${ }^{\text {c. }}$ \\ ${ }^{a}$ Residente de Psicología, Hospital Dr. Rodríguez Lafora, Madrid, España. ${ }^{b}$ Psicóloga Clínica, Centro \\ de Salud Mental de Hortaleza, Madrid, España. ${ }^{c}$ Profesora Titular. Dpto. de Ps. Básica II, Facultad de \\ Psicología, UNED, España.
}

Correspondencia: María Teresa Rosique (m.rosique@madrid.uned.es)

Recibido: 04/11/2013; aceptado con modificaciones: 29/03/2014

RESUMEN: Partiendo de la teoría, técnica y práctica
del Acompañamiento Terapéutico en el presente artí-
culo se va a abordar un caso de la planta de larga estan-
cia de un hospital psiquiátrico. Allí se instaura, dentro
de una estrategia más amplia de trabajo multidiscipli-
nar y psicosocial, un programa de Acompañamientos
para pacientes con trastorno mental grave, concre-
tamente para trastornos psicóticos y afectivos. En el
Caso M se trabaja en coordinación con su familia con
el objetivo último de que pueda retomar su autonomía
y ser dada el alta. Tras un año de Acompañamiento
Terapéutico se aprecia una pronunciada mejoría, tanto
a nivel funcional como social.

PALABRAS CLAVE: Acompañamiento Terapéutico, hospital psiquiátrico, trastorno mental grave.
ABSTRACT: In this article one case is going to be addressed from the theory, technique and practice of the Therapeutic Accompaniment. The program has been established within a plant of long stay of a psychiatric hospital, inside a more wide strategy of multidisciplinary work. The target population of the program are patients with a severe chronic mentally illness, particularly with psychotic and affective disorders. In the Case M the work has been made in coordination with the family in order to be able to return the autonomy and be discharged from the hospital. After a year of Therapeutic Accompaniments an improvement can be appreciated at functional and social levels.

KEY WORDS: Therapeutic Accompaniment, psychiatric hospital, severe mental illness.

\section{Introducción .}

Genéricamente podría definirse el acompañamiento terapéutico (AT) como una práctica sociocomunitaria con funciones rehabilitadoras que suele emplearse como técnica complementaria dentro de estrategias multidisciplinarias de intervención. En este sentido, su principal escenario es la calle, entendida como contexto cotidiano y considerando que ahí emergerán menos resistencias, dado que se intenta evitar cualquier tipo de artificialidad terapéutica e institucionalización como consecuencia del ingreso prolongado.

El AT surgió en la década de los sesenta en Argentina como una alternativa y reacción a la internación cerrada y la marginación social consecuente. Poco a poco 
se ha ido expandiendo a otros ámbitos (educativos, asistenciales, judiciales...), buscando favorecer la integración social, la resocialización, la toma de contacto con el exterior y potenciando el desarrollo de la autonomía del paciente (1).

En cuanto al marco teórico de referencia del AT hoy en día se mantiene cierta precariedad. Parte de un enfoque psicoanalítico, de la teoría de relaciones objetales, concretamente algunos autores extrapolaron las ideas de Winnicott (2) respecto a la experiencia paradójica del infante de estar solo en presencia de la madre; este concepto se retoma ya que se trataría de crear "un espacio en donde el sujeto tenga la posibilidad de elegir, de planificar, de proponer, de decidir qué hacer con esos momentos libres que tiene dentro de la institución, estimulando el deseo personal y grupal" (3), aspectos que van desapareciendo con la rutina de la institución. En este sentido, se describe la tarea del acompañante y el vínculo afectivo como la de "escuchar su palabra real o simbólica para acompañarlo en su deseo" (4) y "mostrar al paciente, in situ, las diferentes formas de actuar y reaccionar frente a las vicisitudes de la vida cotidiana" (5). En definitiva, el apoyo, la contención y el sostén cobran gran relevancia en el presente contexto por lo que se hace imprescindible la creación de un espacio de confianza y clima de seguridad. Además de estos elementos, se debe hacer referencia a la importancia del encuadre, configurado a su vez por "tres ejes organizadores: el espacio, el tiempo y la actitud mental y conductual del acompañante" (6).

Hemos pretendido dar unas pinceladas sobre el AT, sin olvidar que es una técnica que debe encuadrarse dentro del trabajo más amplio de un equipo multiprofesional que atienda todas las necesidades del paciente pero que, a su vez, pretende "desinstitucionalizarlo". Se va a presentar un caso clínico abordado desde un programa de AT llevado a cabo en una institución psiquiátrica pública. Semanalmente y durante doce meses se realizaron los sucesivos acompañamientos oscilando entre hora y media y tres horas de duración, y con unos objetivos fijados previamente que variaban según la evolución observada.

\section{Caso clínico.}

M es una mujer de 66 años ingresada hace 7 años en una planta de rehabilitación a través de su Centro de Salud Mental en donde realizaba seguimiento regular desde hacía más de dos décadas.

Nace en una pequeña localidad y es la tercera de seis hermanos. Su madre fallece cuando tiene 12 años y se hace cargo de las tareas del hogar. Con 18 años contrae matrimonio y a los 24 y 28 años tiene sus a dos hijas. Tras el primer nacimiento aparece la primera descompensación maniaca cargada de sintomatología delirante 
NOTAS CLÍNICAS

de perjuicio respecto a su marido, precisando ser ingresada, y es diagnosticada de psicosis maniaco-depresiva y cuadro psicótico puerperal. Permanece asintomática siete años, tras los que sufre numerosos ingresos por episodios maníacos y de agresividad contra sus familiares. Ha recibido múltiples tratamientos farmacológicos, con estabilizadores del ánimo y antidepresivos, que se han mostrado poco eficaces. Antes del ingreso en la planta de cuidados psiquiátricos prolongados convivía con su hija y su marido, que refieren que resultaba complicada su contención y la convivencia en el medio familiar.

\section{Intervención.}

Tras tres años de su ingreso en la planta de rehabilitación, es reubicada en la unidad de larga estancia dado que los objetivos de su plan individual de rehabilitación no han sido alcanzados, en cuanto a estabilización de su psicopatología (concretamente reducción de la clínica maniaca y episodios agresivos), instauración de rutinas y compromisos, potenciación de su autonomía, establecimiento de relaciones sociales y afectivas para superar su aislamiento e inhibición y, en definitiva, para lograr su vuelta al entorno familiar.

En la planta de larga estancia empeora su sintomatología permaneciendo durante meses mutista, sin expresividad facial ni visual y con miedo al contacto físico en la habitación de observación. La preocupación del equipo por el retroceso de M y la cronicidad e irreversibilidad a la que apunta el caso lleva a proponer su derivación al programa de AT del hospital planteándonos los objetivos siguientes: generalizar la rehabilitación a contextos naturales en un clima contenedor pudiendo salir del recinto, crear un vínculo afectivo y un espacio relacional seguro en el que pueda ser autónoma, promover habilidades sociales e instrumentales de la vida diaria y aumentar la conciencia de sus responsabilidades para evitar el aislamiento. Si bien inicialmente se muestra receptiva al acompañamiento, manifestando cierta alegría y deseo de salir del recinto hospitalario, enseguida afloran sus ansiedades y miedos más profundos que manifiesta a través de conductas como a rechazo al terapeuta, a cruzar el puente en la salida del hospital, al autobús, al ascensor, a pedir la merienda, a quedarse sin dinero y, desgraciadamente, a no poder volver al hospital, único lugar que le brinda un sentimiento de seguridad y confianza. Una vez analizadas sus conductas y vuelto a replantear el tipo de acompañamiento que precisa $\mathrm{M}$, se decide pautar cuidadosamente todas las intervenciones, realizando un reencuadre de los espacios y tiempos: pasear por la planta, por los alrededores del hospital, reducir el tiempo de acompañamiento y ampliar su frecuencia. Asimismo, se solicita la colaboración de la familia; el marido, tras una amarga retahíla de re- 
proches, ambivalencias entre ayudar y el temor a la recaída, decide incorporarse al programa y acudir en algún acompañamiento.

Resultados.

$\mathrm{M}$ es un claro modelo de la necesidad de respetar los espacios y los tiempos en esta práctica. Se intentó calmar su ansiedad remarcando que los AT serían intrahospitalarios y se respetaría sus tiempos de adaptación, pues al pasear por la ciudad surgen las comentadas resistencias. Tras permanecer unos meses por la unidad y pasear por el recinto, paulatinamente se empezaron a dar paseos entorno al hospital y por la ciudad en compañía de su marido con el fin de que en un futuro pudiera volver a su hogar y saberse desenvolver. Mientras que al inicio mostraba un nulo contacto con lo emocional y lo corporal, ciñéndose a hablar sobre temas de la institución, la comida, los grupos, los profesionales, pasados ocho meses de acompañamientos $\mathrm{M}$ pasa de tolerar la presencia del terapeuta a valorarle y esperarle. Además comienza a expresar algunos de sus sentimientos "me quiero ir del hospital, ya me encuentro mejor, llevo mucho tiempo y quiero estar con mi familia...", para con el tiempo llegar a afirmar "quizá ellos tengan miedo de que me ponga mal, yo también lo tengo, pero aquí no puedo quedarme toda la vida...”. A los diez meses $\mathrm{M}$ empieza a realizar breves visitas a su casa (lo que llevaba siete años sin hacer), dos meses más tarde permanece cuatro días en su hogar y actualmente acude periódicamente los fines de semana. Paralelamente comienza a responsabilizarse de distintas tareas del hogar, del cuidado de sus hijas y nietos, de la toma de medicación y, en definitiva, de su proyecto vital: poder volver a su hogar.

Tras un año de vínculo terapéutico a través del AT en los que el tratamiento farmacológico se ha mantenido constante, se han podido observar modificaciones destacables en el comportamiento de $\mathrm{M}$ en lo que respecta a superar sus propios miedos, en la relación activa con el terapeuta, en la convivencia con su entorno familiar desde donde se percibe una mejoría y buena integración, lo que ha conllevado una estabilización de su sintomatología.

\section{Discusión}

En palabras de Dozza (7) "muchas veces uno trabaja en el psiquiátrico y dice: aquí no es posible hacer un trabajo de inserción social, porque no nos dejan salir con los pacientes. Pero eso no es necesariamente cierto; porque si se tiene 
en cuenta que lo social es un espacio vincular, incluso dentro del psiquiátrico es posible realizar una labor de inserción social.

Haciéndonos eco de esta afirmación, si bien éramos conscientes de las limitaciones que supone trabajar con pacientes ingresados durante las 24 horas en instituciones psiquiátricas y, por ello, imbuidos en el propio sistema, cuando nos planteamos la intervención que acabamos de describir, lo hicimos desde la incertidumbre de si aún era posible recuperar de alguna forma a una paciente que presentaba un retroceso, que pensamos, estaba en parte vinculado a la hospitalización, así como desde la ilusión de intentar una nueva intervención terapéutica dando una nueva luz al caso a través de los AT.

Tal y como hemos expuesto la cronicidad del caso que nos ocupa el deterioro y aislamiento subsecuente, nos ha llevado a plantearnos esta intervención con el fin de establecer un vínculo afectivo y una presencia institucional no intrusiva para impulsar el proyecto vital, las necesidades y los deseos de una paciente con psicosis maníaco-depresiva con una larga institucionalización. Con el AT se ha podido aprovechar el espacio de $\mathrm{M}$ adecuándolo a sus necesidades y a su momento lo que le ha permitido compartir sus deseos y hacerse cargo de sus proyectos vitales. No podemos acabar sin destacar que se han logrado recuperar capacidades tales como la expresión afectiva y el deseo de vinculación que se hallaban camufladas bajo el manto de las tan arraigadas rutinas de la institución que provocan que se vayan sutil y paulatinamente debilitando las potencialidades del paciente de ingreso prolongado.

BIBLIOGRAFÍA:

(1) Saiz, J. y Chévez, A. La intervención Socio-Comunitaria en Sujetos con Trastorno Mental Grave y Crónico: Modelos Teóricos y Consideraciones Prácticas. Revista de Intervención Psicosocial, 2009; 18 (Suppl 1): 75-88.

(2) Winnicott, D.W. The Capacity to be Alone. International Journal of Psychoanalysis 1958; 39: 416-20.

(3) Suárez, M. y Palleiro, L. El espacio de paseos en Hospital de Día. Ponencia presentada en I Jornadas Salud Mental y Derechos Humanos, Paraná, Brasil, 2009.

(4) Merchán, E. Acompañamiento a personas con demencia en una vivienda compartida de mayores. Área 3. Cuadernos de Temas Grupales e Institucionales 1999, 7: 4-13.

(5) Kuras de Mauer, S. y Resnizky, S. Acompañantes Terapéuticos. Actualización teóricoclínica. Buenos Aires: Letra Viva, 2003.

(6) García de Bustamante, E. El acompañamiento terapéutico. En C. Escudero y P. Balanza (Coords.), Manual del Residente en Psicología Clínica, (pp 309-316). Madrid: Asociación Española de Neuropsiquiatría, 2012.

(7) Dozza de Mendonça, L. Lo social es un lugar que no existe: reflexiones desde el acompañamiento terapéutico de pacientes psicóticos. Infocop 1999, 72: 51-4. 